\title{
APOSENTADORIA POR INVALIDEZ: SUA CESSAÇÃO E RETORNO AO MERCADO DE TRABALHO
}

\author{
RETIREMENT BY DISABILITY: THEIR CESSATION AND RETURN TO \\ THE LABOR MARKET
}

Eliane Klesener de OLIVEIRA ${ }^{1}$

ISSUE DOI: $10.21207 / 1983.4225 .369$

\section{RESUMO}

A presente publicação tem por objetivo analisar o retorno do segurado ao mercado de trabalho quando ao passar por um longo período aposentado por invalidez decorrente de doença incapacitante for considerado apto a retornar. Enfrentará grandes dificuldades por estar desatualizado mediante a crescente evolução do mercado de trabalho e também por estar em desvantagem com demais candidatos para uma possível concorrência.

Palavras-Chave: Aposentadoria por Invalidez, Retorno ao Mercado de Trabalho, Incapacidade, Reabilitação Profissional, Incapacidade Social.

\section{ABSTRACT}

This paper is to analyze the return of the insured to the labor market when they go through a long period retired due to invalidity due to incapacitating illness is considered fit to return. It will face great difficulties because it is outdated by the increasing evolution of the labor market and also by being at a disadvantage with the other candidates for possible competition.

Keywords: Retirement for Disability, Return to the Labor Market, Disability, Vocational Rehabilitation, Social Disability.

${ }^{1}$ Pós-graduada em Direito Previdenciário pela Universidade Anhanguera - Uniderp. Graduada em Direito pela Universidade Metodista de Piracicaba (UNIMEP), Piracica$\mathrm{ba} / \mathrm{SP}$. 


\section{INTRODUÇÃO}

Desde os primórdios o ser humano busca o sustento de si e de seus dependentes, inicia cedo sua atividade profissional, buscando sempre melhorar de vida: estuda, trabalha, se especializa para alcançar os mais altos degraus na profissão. Isso parece normal para a maioria das pessoas, uma busca incessante para melhorar a sua qualidade de vida e dos seus. Só que muitas vezes a situação foge do seu controle, surge algo que não está nos planos de ninguém: uma enfermidade ou acidente que o torna incapaz de continuar. E é nisso que consiste a função da Previdência Social, amparar o segurado quando acometido por um risco social, nesse caso a doença incapacitante ou acidente que o tornou incapaz, e que é amparado pelo benefício da Aposentadoria por Invalidez.

Numa situação como essa, o segurado vai parar a busca pelos seus objetivos, de lutar pelo sonho de conquistar uma vida melhor para si e seus dependentes, para lutar contra algo que quer justamente acabar com seus sonhos e objetivos: uma incapacidade.

Muitos neste momento não terão sucesso e terão findada a sua busca, enquanto que outros irão lutar para vencer essa incapacidade. Só que essa luta pode demorar muito tempo, longos anos.

É nisto que consiste o objetivo deste trabalho, analisar este lapso temporal em que o segurado lutou para vencer a enfermidade, lutou para se manter vivo, e recuperando sua saúde, será que tem condições de retornar ao mercado de trabalho perante as constantes transformações que muitas áreas do mercado sofrem?

Ademais, uma longa trajetória foi percorrida para chegar ao grau de conhecimento para a função que este segurado desempenhava no momento em que foi acometido por uma incapacidade, fazendo com que o mesmo parasse no tempo, ou seja, não estivesse presente à evolução do mercado de trabalho. Assim, é justo o segurado ter que traçar toda a trajetória novamente? Terá ele condições de percorrer tudo novamente? Até porque muitas vezes a idade já não ajuda mais para correr atrás de seus objetivos, para recomeçar do zero, e tendo que concorrer com os mais jovens cheios de saúde, de sonhos e atualizados.

Muitos beneficiários da Aposentadoria por Invalidez retornam ao trabalho voluntariamente, e consequientemente perdem o benefício quando o sistema detecta estes casos. Algumas vezes ocorrem por denúncia, que será verificada e se comprovada cessará o benefício. 
Outros têm seu benefício cessado quando o INSS mediante perícia comprova sua recuperação e o segurado deve retornar ao trabalho.

Assim, a intenção da pesquisa é abrir uma discussão mais ampla em relação à temática, visto que é um assunto pouco abordado pela doutrina.

A concessão da aposentadoria por invalidez deveria visar entre outras benesses, uma mudança na qualidade de vida do trabalhador, e não somente um benefício concedido na expectativa de piora no quadro de saúde e conseqüente óbito.

A pesquisa tem a intenção de trazer à tona a conscientização da realidade enfrentada pelo segurado que venha a se encontrar uma situação como esta, em especial nas áreas como, por exemplo, em que a tecnologia através da informática e automação industrial sofre mudanças radicais, e o segurado que retornar ao mercado, talvez não tenha condições para tanto em função de estar afastado por anos e sua reintegração vai requerer investimentos patronais em cursos e treinamentos.

Portanto a pesquisa não tem a intenção de exaurir o assunto, mesmo porque não encontramos na doutrina estudos aprofundados sobre o mesmo. Visa analisar como o trabalhador irá enfrentar essa situação de desatualização, certamente não servirá mais para exercer o cargo sem que se aprofunde novamente nos estudos e aprendizagem da prática, pois estará desatualizado sem possuir nenhuma capacidade para exercer sua função.

Mesmo porque o empregador também ficará numa situação difícil, pois para ele o retorno do empregado não lhe trará vantagem alguma.

E mesmo que recomece tudo outra vez no caso de não se adaptar às mudanças na empresa em que trabalhava, terá ele condições de auferir uma remuneração condizente àquela que recebia antes da incapacidade?

Como o benefício da aposentadoria por invalidez não possui característica de definitivo, sendo considerada provisória pelo fato de o segurado a qualquer tempo com a recuperação de sua capacidade ter a mesma cessada, tem a pesquisa como objetivo analisar se em alguns casos específicos não deva, este benefício, ser definitivo. 


\section{APOSENTADORIA POR INVALIDEZ}

\subsection{DEFINIÇÃO DE APOSENTADORIA POR INVALIDEZ}

A aposentadoria por invalidez é um direito garantido pela Constituição Federal em seu artigo 201:

Art. 201. A previdência social será organizada sob a forma de regime geral, de caráter contributivo e de filiação obrigatória, observados critérios que preservem o equilíbrio financeiro e atuarial, e atenderá, nos termos da lei, a: (Redação dada pela Emenda Constitucional $\mathrm{n}^{\circ}$ 20, de 1998) (Vide Emenda Constitucional $n^{\circ} 20$, de 1998).

I - cobertura dos eventos de doença, invalidez, morte e idade avançada; (Redação dada pela Emenda Constitucional $\mathrm{n}^{\mathrm{o}} 20$, de 1998). ${ }^{2}$

É um benefício de natureza previdenciária, restrito aos contribuintes, trabalhadores, do sistema. É concedido ao trabalhador que se tornar incapaz de exercer qualquer atividade laborativa, e que também não possa ser reabilitado em outra profissão, mediante avaliação pericial médica do INSS. Conforme aduz o artigo 42 da Lei 8.213/91:

Art. 42. A aposentadoria por invalidez, uma vez cumprida, quando for o caso, a carência exigida, será devida ao segurado que, estando ou não em gozo de auxílio-doença, for considerado incapaz e insusceptível de reabilitação para o exercício de atividade que lhe garanta a subsistência, e ser-lhe-á paga enquanto permanecer nesta condição. ${ }^{3}$

Podendo ser reavaliado a cada dois anos, o benefício será pago enquanto durar a incapacidade.

\footnotetext{
2 BRASIL. Constituição Federal de 1988. Disponível em: www.planalto.gov.br/ccivil_03/ Constituicao/Constituicao.htm. Acesso em 13/10/2015.

BRASIL. Lei dos Benefícios 8.213/91. Disponível em: < www.planalto.gov.br/CCIVIL_03/leis/L8213cons.htm> Acesso em 13/09/2015.
} 
Segue o fundamento legal os artigos seguintes até o artigo 47 da Lei n. 8.213/91 e artigos 43 a 50 do Decreto 3.048/99.

Em regra, primeiramente o cidadão deve requerer um auxíliodoença, que possui os mesmos requisitos da aposentadoria por invalidez. Contudo, sendo caso grave, não é necessária a concessão prévia do auxílio-doença, podendo diretamente ser contemplado pela aposentadoria por invalidez. Constatada a incapacidade permanente para o trabalho pela perícia-médica e sem a possibilidade de reabilitação em outra função, a aposentadoria por invalidez será indicada.

Para tanto, um requisito deverá ser observado para se adquirir a aposentadoria por invalidez: o cidadão não terá direito, se no momento de sua filiação à Previdência Social já for portador de doença ou lesão que geraria tal benefício, a não ser quando a incapacidade resultar no agravamento da enfermidade. A isto chama-se incapacidade pré-existente.

A perícia médica será feita de dois em dois anos para confirmar a permanência da incapacidade para o trabalho. Esta periodicidade cessará quando o cidadão completar 60 anos (isenção dada pela Lei n. 13.063/2014).

Entretanto, os proventos relacionados à aposentadoria por invalidez, cessarão quando o segurado recuperar a capacidade laboral e/ou voltar ao trabalho.

Ocorrendo a recuperação da saúde e constatada a capacidade para a atividade laboral, o segurado retornará, conforme diploma legal, Lei 8.213/91:

Art. 47. Verificada a recuperação da capacidade de trabalho do aposentado por invalidez, será observado o seguinte procedimento:

I - quando a recuperação ocorrer dentro de 5 (cinco) anos, contados da data do início da aposentadoria por invalidez ou do auxílio-doença que a antecedeu sem interrupção, o benefício cessará:

a) de imediato, para o segurado empregado que tiver direito a retornar à função que desempenhava na empresa quando se aposentou, na forma da legislação trabalhista, valendo como documento, para tal fim, o certificado de capacidade fornecido pela Previdência Social; ou 
b) após tantos meses quantos forem os anos de duração do auxílio-doença ou da aposentadoria por invalidez, para os demais segurados;

II - quando a recuperação for parcial, ou ocorrer após o período do inciso I, ou ainda quando o segurado for declarado apto para o exercício de trabalho diverso do qual habitualmente exercia, a aposentadoria será mantida, sem prejuízo da volta à atividade:

a) no seu valor integral, durante 6 (seis) meses contados da data em que for verificada a recuperação da capacidade;

b) com redução de $50 \%$ (cinquenta por cento), no período seguinte de 6 (seis) meses;

c) com redução de $75 \%$ (setenta e cinco por cento), também por igual período de 6 (seis) meses, ao término do qual cessará definitivamente. ${ }^{4}$

Verifica-se a possibilidade de retorno quando o segurado que recuperar a saúde dentro de cinco anos, cessando o benefício imediatamente quando este tiver direito de retornar à função que desempenhava na empresa onde se aposentou. E se a recuperação da saúde for parcial ou ocorrer após 5 anos, ocorrerá segundo as alíneas do inciso II: o benefício será devido integralmente durante 6 meses, será de $50 \%$ nos meses seguintes e $75 \%$ pelos 6 meses restantes.

Conforme o artigo 45 da Lei 8213/91 o segurado que necessitar ser assistido por outra pessoa receberá um acréscimo de $25 \%$ sobre o benefício, sem estar limitado pelo valor do teto, como ocorre com os demais cálculos de benefícios.

Ocorre que apesar de a lei prever várias possibilidades em favor do segurado, a realidade no caso concreto pode ser bem diferente. Será que o segurado tem realmente capacidade de retornar ao trabalho em todas as situações?

Segundo Daniel Pulino (2001), quando ocorrer a revisão da aposentadoria por invalidez conforme previsão no artigo 71 da Lei $8.212 / 91$, não é somente o quadro clinico do segurado que deve ser avaliado, mas também a sua capacidade de ganho, ou seja, terá o mesmo con-

\footnotetext{
4 BRASIL. Lei dos Benefícios 8.213/91. Disponível em: < www.planalto.gov.br/CCIVIL_03/leis/L8213cons.htm> Acesso em 13/09/2015.
} 
dições de ter novamente uma remuneração que esteja dentro da média que garantia sua subsistência e de seus dependentes?

\section{- CARÁTER NÃO DEFINITIVO DA APOSEN- TADORIA POR INVALIDEZ - SUSPENSÃO DO CONTRATO DE TRABALHO}

A aposentadoria por invalidez não possui caráter definitivo, ou seja, ela subsistirá provisoriamente até que mediante perícia seja detectada a cura da enfermidade e a capacidade de retorno à atividade laboral. Mas, no entanto, nem sempre foi assim.

A sumula 217 do STF trata da possibilidade da aposentadoria por invalidez se tornar definitiva quando o aposentado não tivesse sua capacidade recuperada dentro do prazo de cinco anos: Sumula 217: "Tem direito de retornar ao emprego, ou ser indenizado em caso de recusa do empregador, o aposentado que recupera a capacidade de trabalho dentro de cinco anos, a contar da aposentadoria, que se torna definitiva após esse prazo" 5 . Assim, depois de decorridos cinco anos sem o beneficiário ter recuperada sua capacidade, sua aposentadoria se tornava definitiva. Só que o que ocorria era a extinção do contrato de trabalho com a empresa a qual laborava quando do início da sua incapacidade.

Segundo Zambitte (2015) é comum ainda se ouvir falar que em cinco anos a aposentadoria por invalidez se torna definitiva, mas a partir do advento da LOPS (Lei Orgânica da Previdência Social), deixou de existir.

A Sumula 160 do TST também modificou a questão defendendo a não extinção do contrato de trabalho, argumentando a segurança do trabalhador de ter seu emprego garantido em caso de recuperação, extinguindo-se assim a possibilidade da aposentadoria por invalidez se tornar definitiva. Sumula 160: "Cancelada a aposentadoria por invalidez, mesmo após cinco anos, o trabalhador terá direito de retornar ao emprego, facultado, porém, ao empregador, indenizá-lo na forma da lei." 6 Assim, este benefício que possuía um prazo para se tornar definitiva, com a edição da referida sumula não possui mais prazo, trazendo uma insegurança para o incapacitado em diversas situações.

\footnotetext{
5 Súmulas: STF - Supremo Tribunal Federal. Disponível em: www.stf.jus.br/portal/cms/verTexto.asp?servico=jurisprudenciaSumula. Acesso em 15/12/2015.

${ }^{6}$ Súmulas - TST. Disponível em: www.tst.jus.br/sumulas. Acesso em 15/12/2015.
} 
Assim que o segurado é aposentado por invalidez, ocorre a suspensão do contrato de trabalho, ou seja, ficará suspenso, sem auferir remuneração da empresa, enquanto subsistir a incapacidade do mesmo. No entanto, perceberá o benefício de aposentadoria por invalidez que é no importe de $100 \%$ do salário de benefício, calculado sobre os 80 maiores salários de contribuição e sem incidir sobre o mesmo, fator previdenciário.

Segundo Fábio Zambitte Ibrahim, não ter uma previsão do término do benefício acaba gerando muitas complicações, uma delas é a não previsão do término do contrato de trabalho, pois ao empregador gera uma situação complicada. Para o autor, a aposentadoria por invalidez deveria cessar o contrato de trabalho, pois se o segurado retornar, ou seja, se ele recuperar a capacidade, a lei permite que o empregador faça isso, então para o mesmo, porque não no momento da aposentadoria, conforme aduz: "De qualquer forma, o ideal, de lege ferenda, seria a aposentação por invalidez terminar de imediato o contrato de trabalho." (IBRAHIM, 2015, pg. 596).

No entanto, temos que admitir que apesar de não ser vantajosa para o empregador a continuação do vínculo, para o segurado é vantajoso, e uma das vantagens é a manutenção do plano de saúde, afinal nada mais justo que a empresa ajude a arcar com os gastos de seu tratamento, pois adoecer não é algo que se planeja. Imagine como seria ficar sem o plano de saúde no momento em que mais precisará dele.

Conforme explicitado por Rúbia de Alvarenga em seu artigo: "A concessão de plano de saúde, ainda, representa parte integrante do contrato de trabalho do empregado, devendo permanecer, mesmo com a suspensão do seu contrato de trabalho, conforme já estabelecido pela jurisprudência predominante do TST." 7

No mesmo sentido a jurisprudência demonstrada no artigo, declarando o direito à indenização por dano moral ao segurado em caso de supressão do plano de saúde pela empresa:

RECURSO DE REVISTA. REPARAÇÃO POR DANOS MORAIS. INDENIZAÇÃO. SUPRESSÃO

\footnotetext{
${ }^{7}$ ALVAREnGA, Rúbia Zanotelli de Alvarenga. A Aposentadoria por Invalidez e a Manutenção do Plano de Saúde. (Artigo enviado como material de estudo da aula 03 de Benefícios por Incapacidade). Disponível

em: http://www.facefaculdade.com.br/arquivos/revistas/A_Aposenntadoria_por_Invalidez_e_a_Manuteno _do_Plano_de_Sade.pdf.
} 
DO PLANO DE SAÚDE APÓS A APOSENTADORIA POR INVALIDEZ. A supressão do plano de saúde garantido aos demais funcionários justamente no momento em que o empregado se encontra afastado, em aposentadoria por invalidez, momento em que mais necessita do benefício, acarreta sentimento de angústia, pois inviabiliza os meios para tratar da sua saúde, a denotar ato ilícito do empregador, a ser reparado. Recurso de revista conhecido e provido. (TSTRR-2039-76.2010.5.12.0028, Relator Ministro Aloysio Corrêa da Veiga, $6^{\text {a }}$ Turma, DJ de $02 / 12 / 2011 .^{8}$

Portanto somente a questão de ter o amparo do plano de saúde já demonstra o lado positivo da manutenção do contrato de trabalho.

Mas retornando a questão anterior, bem verdade é que o trabalhador que passa um longo período fora do mercado de trabalho, ao retornar talvez não seja mais útil para a empresa, restando ao seu empregador a única possibilidade que lhe resta e que é garantida pela lei, de indenizá-lo e extinguir o contrato de trabalho, ou seja, não existe uma garantia de que este trabalhador conseguirá manter o mesmo emprego, que desempenhará novamente sua função, auferindo os mesmos proventos. Assim, não sendo mais útil à empresa o mesmo será demitido. Questão que será tratada a seguir.

\footnotetext{
${ }^{8}$ Ibdem.
} 


\section{2 - CESSAÇÃO DA APOSENTADORIA POR INVALIDEZ - INSEGURANÇA ENFRENTADA PELO SEGURADO}

Como já descrito não será nada fácil ao segurado o seu retorno ao mercado de trabalho, ele poderá enfrentar diversas situações. Analisemos algumas que poderão trazer total insegurança para o mesmo:

Pensemos em uma situação em que o beneficiário que teve seu contrato de trabalho suspenso e sua incapacidade perdurou por longo lapso temporal e neste momento tem o seu benefício cessado. Tendo uma recuperação total da capacidade retornará à empresa que ele laborava em sua função, tratemos de uma função onde a tecnologia evolui muito, sabemos que cinco anos no mínimo já ocorrem mudanças radicais, imagine se ocorreu mais tempo, $10 \mathrm{ou}$ 15 anos, certamente ele não estará atualizado para assumir a sua função, mesmo porque um curso para se atualizar em caso de uma reabilitação é bastante extenso e caro. Assim neste caso este empregado não terá mais nenhuma utilidade para o empregador, tendo o mesmo que indenizá-lo e demiti-lo.

Agora vejamos o seguinte, depois de este empregado ter sido mandado embora (claro tendo recebido a indenização), ele terá que procurar um novo emprego. Parece ser simples, mas pode não 
ser, pensemos na situação deste segurado já ter alcançado uma idade um pouco avançada, sabemos que no mercado de trabalho isso pesa muito diante da concorrência que se enfrenta na busca por um emprego.

Até aqui vimos que esta pessoa já está com duas desvantagens: a idade e a desatualização no mercado de trabalho. Sem contar que seu histórico não ajuda muito, pois a pessoa que teve uma enfermidade que o tornou incapacitado para o labor não é um candidato muito forte para ser contratado.

E apesar de toda esta situação, se o mesmo conseguir um novo emprego, ele terá uma remuneração que seja compatível com o nível de vida que tinha e que mantinha sua subsistência e a de seus familiares quando do início de sua incapacidade?

Segundo Daniel Pulino:

...deve-se avaliar a concreta possibilidade de o segurado retirar do próprio trabalho renda suficiente para manter sua subsistência em patamares, senão iguais, ao menos compatíveis com aqueles que apresentavam antes de sua incapacitação e, que foram objetivamente levados em consideração no momento de quantificação das suas contribuições para o sistema... considerar, nesse juízo, as condições pessoais do segurado, confrontando-as com a possibilidade de engajamento em atividade laborativa apta a lhe garantir o nível de subsistência pertinente. (PULINO, 2001, pg. 62).

Ou seja, num possível retorno à atividade, devem ser consideradas as possibilidades e garantias para que o beneficiário tenha 
condições de retornar e ter uma vida digna para si e seus dependentes.

Assim, far-se-á necessária uma avaliação de uma junta médica, psicólogos, assistentes sociais, analisando as condições pessoais do beneficiário dentro do seu contexto social, sua idade, limitações físicas, grau de instrução, aptidões, possível diminuição de renda que pode ocorrer, tudo levando em consideração o princípio da dignidade humana.

É nesse sentido que julgou o Tribunal Regional Federal da $5^{\circ}$ região, retirado do site de jurisprudências Jusbrasil:

A questão relativa à concessão de beneficio da espécie Aposentadoria por Invalidez deve ser analisada casuisticamente, considerando-se a situação individual do segurado, a fim de se aproximar, o máximo possível, do ideal de justiça. Tendo-se em vista a idade do recorrido, sua condição intelectual, bem como a física, isso nos levaria a crer na total desarmonia entre o que se pretende e a realidade fática e social nacional. Se para uma pessoa fisicamente sadia, com um bom nível cultural já é difícil conseguir emprego nos dias atuais, quanto mais para um deficiente físico, de nível elementar, com aproximadamente quarenta anos de idade. (TRF-5 - Apelação Cível: AC 46978 RN 94.05.10086-6). ${ }^{9}$

Ocorre que, para avaliação da possibilidade de cessação do benefício de aposentadoria por invalidez, cada caso concreto deve ser minuciosamente analisado, para que nem uma injustiça venha a ocorrer, mesmo porque se o benefício foi concedido, é porque se

\footnotetext{
9 Jurisprudências: trecho retirado de um julgado. Disponível em: www.jusbrasil.com.br/.../busca?...reabilitação+profissional\%2C...aposent...> Acesso em 24/11/2015.
} 
chegou à situação última de o segurado ter sido considerado incapacitado, fazendo jus à aposentadoria por invalidez. Como descreve Fábio Zambitte Ibrahim: "Embora a aposentadoria por invalidez seja reversível, a sua concessão demanda firme convicção da provável irreversibilidade da inaptidão do segurado. Do contrário, permanecerá no auxílio-doença, independentemente de prazo." Ao fazer o autor uma comparação entre os dois benefícios. (IBRAHIM, pg. 645, 2015).

\section{4 - DA OBRIGAÇÃO DO INSS E EMPRESAS EM FORNECER REABILITAÇÃO PROFISSIONAL SOB PENA DE RENOVAÇÃO DO BENEFÍCIO}

A legislação brasileira prevê a obrigatoriedade de o INSS fornecer reabilitação profissional ao segurado que retornar à atividade. Esta previsão encontra-se no artigo 89 (e seguintes) da Lei 8213/91:

Art. 89. A habilitação e a reabilitação profissional e social deverão proporcionar ao beneficiário incapacitado parcial ou totalmente para o trabalho, e às pessoas portadoras de deficiência, os meios para a (re)educação e de (re)adaptação profissional e social indicados para participar do mercado de trabalho e do contexto em que vive. ${ }^{10}$

\footnotetext{
10 BRASIL. Lei dos Benefícios 8.213/91. Disponível em: < www.planalto.gov.br/CCIVIL_03/leis/L8213cons.htm> Acesso em 13/09/2015.
} 
O Decreto 3048/99 e a Instrução Normativa 77/15 também trazem a mesma previsão em seus artigos 136 em diante e 348 em diante, respectivamente. O artigo 399 da IN 77/15 descreve quem faz jus a este benefício, onde está inserido o aposentado por invalidez:

Art. 399. Poderão ser encaminhados para o Programa de Reabilitação Profissional:

III - o segurado em gozo de aposentadoria por invalidez; ${ }^{11}$

O segurado passará pelo processo de reabilitação, não podendo se negar a fazê-lo, e só retornará a atividade quando estiver apto.

Ao ser considerado reabilitado, receberá um certificado de reabilitação profissional que será fornecido pelo INSS (art. 92 Lei 8213/91). Assim será inserido no mercado de trabalho retornando à empresa em função compatível com a natureza e as causas da inaptidão. Neste momento cessará o benefício e suspensão do contrato de trabalho, reativando o vínculo laboral.

O artigo 139 do Decreto 3048/99 traz também a previsão do desenvolvimento de cursos e treinamentos para a reabilitação profissional firmando contratos e convênios com empresas públicas e privadas, ou seja, é aqui que entra a participação das empresas neste processo:

\footnotetext{
11 INSTRUÇÃO NORMATIVA INSS/PRES No 77, DE 21 DE JANEIRO DE 2015 - DOU DE $22 / 01 / 2015$ - Alterada. Disponível em: www3.dataprev.gov.br/sislex/paginas/38/insspres/2015/77.htm. Acesso em 15/12/2015.
} 
Art. 139. A programação profissional será desenvolvida mediante cursos e/ou treinamentos, na comunidade, por meio de contratos, acordos e convênios com instituições e empresas públicas ou privadas, na forma do art. $317 .^{12}$

O Decreto ainda prevê como será desenvolvido este processo de reabilitação com acompanhamento através de pesquisa, inclusive se o segurado se adaptou (IV).

Art. 137. O processo de habilitação e de reabilitação profissional do beneficiário será desenvolvido por meio das funções básicas de:

I - avaliação do potencial laborativo; (Redação dada pelo Decreto $\mathrm{n}^{\circ} 3.668$, de 2000).

II - orientação e acompanhamento da programação profissional;

III - articulação com a comunidade, inclusive mediante a celebração de convênio para reabilitação física restrita a segurados que cumpriram os pressupostos de elegibilidade ao programa de reabilitação profissional, com vistas ao reingresso no mercado de trabalho; e (Redação dada pelo Decreto $\mathrm{n}^{\circ} 4.729$, de 2003).

IV - acompanhamento e pesquisa da fixação no mercado de trabalho. ${ }^{13}$

No entanto se com o processo de reabilitação profissional o segurado não se recuperar, será reencaminhado à aposentadoria por invalidez.

Percebemos que há previsão na lei, se é colocado em prática caberá analisar.

\section{2 - O MERCADO DE TRABALHO}

\footnotetext{
${ }^{12}$ BRASIL. Decreto 3.048/99. Disponível em: < www.planalto.gov.br/ccivil_03/decreto/d3048.htm > Acesso em 13/09/2015.

${ }^{13}$ Ibdem.
} 


\section{1 - CRESCENTE TRANSFORMAÇÃO DO}

\section{MERCADO DE TRABALHO}

As mudanças tecnológicas ocorrem com muita rapidez e afeta diretamente o mercado de trabalho, nos dias atuais para a pessoa se manter em um emprego precisa estar constantemente se atualizando com cursos de especialização para não ser substituído por aqueles que se dedicam a isso. Em um estudo realizado de Direito do Trabalho, apresentado em forma de artigo, o autor apresenta a velocidade em que a História corre por conta da evolução tecnológica nestes últimos anos. Ele aponta a necessidade que o trabalhador tem de se atualizar para não ser descartado. A pesquisa foi realizada em 2005, sem dúvida as coisas já evoluíram muito depois disso. Vejamos:

As mudanças tecnológicas têm sido meteóricas. $\mathrm{Na}$ década de 70, uma inovação industrial durava, em média, dois anos. Na década de 80 passou a durar apenas um ano. Depois disso tornava-se obsoleta ou era apropriada por grande parte dos concorrentes. $\mathrm{Na}$ década de 90, a duração passou para apenas seis meses. $^{14}$

O autor trata neste artigo sobre várias questões que são afetadas com o avanço das tecnologias, e que para entrar no mercado de trabalho precisa primeiramente de boa educação:

Para acompanhar a sua evolução e tirar o máximo rendimento das novas tecnologias, não basta ser adestrado. É preciso ser educado. A educação de boa qualidade passou a ser uma condição básica para se ajustar os trabalhadores aos novos ambientes de trabalho e às novas tecnologias. ${ }^{15}$

E sabemos que no Brasil a educação não é de boa qualidade, estamos carentes de políticas públicas que garantam um aprendizado efici-

\footnotetext{
${ }^{14}$ Evolução Tecnológica: Repercussões nas Relações do Trabalho. Trabalho apresentado no Ciclo de Estudos de Direito do Trabalho, Angra dos Reis (Rio de Janeiro), 28 de maio de 2005. Disponível em: Artigos: www.josepastore.com.br/artigos/rt/rt_246.htm). Acesso em 04/11/2015.

${ }^{15}$ Ibdem.
} 
ente. Neste mesmo estudo o autor relata uma comparação com outros países:

No Brasil, a força de trabalho tem apenas 5 anos de escola - e má escola. Isso é insuficiente para se acompanhar as mudanças meteóricas que ocorrem no mundo tecnológico. Basta lembrar que a força de trabalho da Coréia do Sul tem 10 anos de escola - e boa escola. A do Japão tem 11; a dos Estados Unidos 12; e a maior parte dos países da Europa tem mais do que isso. ${ }^{16}$

Com esta estatística podemos ver que o nosso País investe muito pouco em qualificação e capacitação do trabalhador: "As tecnologias, de um modo geral, demandam profissionais mais qualificados (Freyssenet, 1990)". E não é o que acontece, pois há sempre uma restrição dos governos no investimento em educação, boa educação. Se o indivíduo quiser ser melhor capacitado terá que investir periodicamente em novos cursos de especialização.

$\mathrm{O}$ autor ainda retrata as previsões de estudiosos referente às mudanças tecnológicas no sentido de diminuição de emprego, o que não se concretizou, pois mesmo ocorrendo diversas mudanças nas relações de trabalho, novos cargos surgiram com a tecnologia, porém, para isso, o indivíduo tem que estar sempre buscando se atualizar no Mercado de trabalho.

Assim retornando ao raciocínio anterior da presente pesquisa, se ocorrem mudanças radicais nas áreas tecnológicas que afetam diretamente o mercado de trabalho e as relações de emprego, trazendo dificuldade para um trabalhador se manter atualizado e conservar seu emprego, quanto mais àquele que por longo período esteve fora do mercado de trabalho, aposentado por invalidez.

\section{RETORNO DO SEGURADO AO MERCADO DE TRABALHO}

\footnotetext{
${ }^{16}$ Ibdem.
} 


\section{1- DIFICULDADES ENFRENTADAS PELO SEgURADO AO RETORNAR AO MERCADO DE TRABALHO}

Cumpre salientar que as dificuldades enfrentadas pelo segurado ao ter que retornar ao trabalho são diversas: insegurança, medo, insatisfação de ter que recomeçar sem saber o que pode surgir daí para frente.

Neste momento vamos descrever algumas decisões de tribunais de diferentes regiões para analisarmos o que ocorre no caso concreto:

Ao julgar um caso de uma pessoa de idade avançada, o TRF da $2^{a}$ região levou em conta a sua idade, transcrevo, assim, a ementa da decisão publicada em site de jurisprudências Jusbrasil:

PREVIDENCIÁRIO E PROCESSUAL CIVIL. RESTABELECIMENTO DE BENEFÍCIO. APOSENTADORIA POR INVALIDEZ. EXAME MÉDICO PERICIAL FAVORÁVEL. - Comprovado por laudo pericial que o segurado encontra-se incapacitado para o trabalho, há que se restabelecer o benefício de aposentadoria por invalidez. Tratandose de restabelecimento de benefício de aposentadoria por invalidez, suspenso pela autarquia previdenciária após 21 anos de sua concessão, o magistrado deve pautar-se não apenas no laudo pericial, mas também nas condições particulares do autor, quais sejam, grau de instrução, idade, nível social, tempo em que esteve afastado do mercado de trabalho por motivo de doença, aliados à conseqüente impossibilidade de reabilitação profissional. - Recurso improvido. ${ }^{17}$

Este caso trata-se de aposentadoria por invalidez que havia sido cessada julgando-se a recuperação da capacidade laboral. Portanto o tribunal entendeu pela inviabilidade de o segurado se reabilitar, concluindo não ser capaz de retornar ao mercado de trabalho devido à situação fática de um modo geral, ou seja, aqui foi analisada a situação como um todo, abrangendo o contexto em que o segurado está inserido.

Também no mesmo sentido o TRF da $4^{\circ}$ região, decisão retirada do site do Jusbrasil:

\footnotetext{
${ }^{17}$ Jurisprudências 
TRF-4 - APELAÇÃO CIVEL AC 1070 RS 2001.71.01.001070-9 (TRF-4)

Data de publicação: 12/01/2005

Ementa: PREVIDENCIÁRIO. RECURSO DO INSS. TEMPESTIVIDADE. INTIMAÇÃOPESSOAL. $\quad$ DESNECESSIDADE. APOSENTADORIA POR INVALIDEZ. INCAPACIDADE PARCIAL E DEFINITIVA. CONDIÇÕES PESSOAIS. CONCESSÃO. TERMO INICIAL. 1...2. Restando demonstrada nos autos a incapacidade do autor para o exercício de sua profissão habitual, e mostrando-se inviável-face às condições pessoais desfavoráveis sua reabilitação profissional, defere-se o benefício da aposentadoria por invalidez. Precedente desta Corte. 3. Termo inicial a contar, no caso, da data do requerimento administrativo, tendo em vista a demonstração de que a incapacidade remonta àquela época. 4. Juros de mora devidos no percentual de $12 \%$ ao ano, ou $1 \%$ ao mês, a contar da citação, em consonância com o entendimento da $3^{\text {a }}$ Seção do E. STJ. ${ }^{18}$

Neste caso ocorreu a concessão do benefício de aposentadoria por invalidez advindo do auxílio-doença, pois foi demonstrada a impossibilidade de reabilitação para retornar à atividade laboral mediante análise das condições pessoais do segurado, longo lapso temporal de afastamento do mercado de trabalho, idade, escolaridade, ou seja, foi analisada a realidade em que o segurado estava inserido.

Lendo o inteiro teor desta decisão, percebe-sei a necessidade de se buscar o benefício pelas vias judiciais, pois o INSS não concedeu por analisar que o segurado não estando com incapacida-

\footnotetext{
${ }^{18}$ Ibdem.
} 
de permanente, tinha condições de retornar, sem dar atenção às particularidades do segurado, ou seja, sem analisar as condições pessoais a que ele estava inserido. Foi o judiciário, no entanto quem teve que dar atenção a isso. No referido caso, o benefício foi concedido e o INSS apelou da decisão, no entanto o STJ deferiu o pedido de concessão, não conhecendo do apelo e negando provimento ao INSS.

\section{2 - A TESE DA INCAPACIDADE SOCIAL}

Apesar de pouco explorada na seara jurídica a tese da incapacidade social é uma questão relevante. Segundo estudo realizado em Dissertação de Pós-graduação, Lindocastro Morais adverte:

Não é apenas a incapacidade física ou psicológica que coloca obstáculos ao exercício de uma atividade laboral, mas a incapacidade social também causa dificuldades ao exercício de um ofício em determinadas circunstâncias até mesmo com força semelhante ou maior que aquela. No caso, a incapacidade social é aquela que engloba fatores além da doença ou lesão, como por exemplo, a idade do trabalhador, local de moradia e escolaridade. ${ }^{19}$

A incapacidade social, segundo a visão do autor, é quando um indivíduo que sofre incapacidade laboral (física, mental, intelectual e sensorial) e em contato com os problemas sociais, é segregado do mercado de trabalho. Situação esta que deve ser considerada pelo perito na sua

\footnotetext{
${ }^{19}$ MORAIS, LINDOCASTRO NOGUEIRA, Dissertação de Pós. Apud RIBEIRO, Juliana de Oliveira Xavier. Atualidades sobre o auxílio-doença. In: FOLMANN, Melissa (coord). Previdência nos 60 anos da declaração de direitos humanos e nos 20 da Constituição Brasileira.Curitiba: Juruá, 2008, pg.189-190.
} 
avaliação, ou seja, as reais condições do segurado devem ser avaliadas. De acordo com Ribeiro apud Morais:

os juízes, quando vão proferir a sentença de concessão do benefício de auxílio-doença, e, principalmente de aposentadoria por invalidez, devem considerar os fatores idade, grau de escolaridade e acesso ao mercado de trabalho. Somente considerando esses fatores sociais, além dos corpóreos, a decisão caminhará rumo ao princípio da dignidade da pessoa humana. ${ }^{20}$

Portanto infelizmente a Previdência Social não tem analisado dessa forma, indeferindo os pedidos de aposentadoria por invalidez em situações como esta, tendo que o segurado buscar na seara judicial a solução para praticamente todas essas situações em que, inclusive sobrecarregando o judiciário. Assim, o INSS reinsere o trabalhador no mercado de trabalho sem avaliar a realidade do caso concreto, ou seja, sua situação dentro do contexto social.

Ainda segundo o autor trata-se de uma enfermidade social, pois o segurado diante de uma situação como esta não tem condições de enfrentar a realidade do mercado de trabalho, não tem condições de se adequar à competição que o mundo globalizado, como o nosso, exige.

O que se espera é que a Previdência Social faça valer seu fundamento constitucional e legislação previdenciária de proteção ao cidadão, reconhecendo a existência da incapacidade social e julgando de forma coerente a realidade do segurado, afinal essa é a sua função, de proteger o segurado para que este não viva à margem da sociedade, dependendo de caridade. Pois foi pra isso que contribuiu quando da sua capacidade. E só assim, sendo amparado em todas as situações, teremos observados o Princípio da Dignidade Humana.

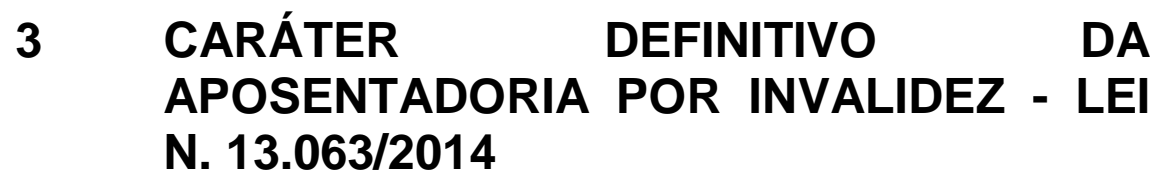

${ }^{20}$ Ibdem. 
A previdência social reserva-se o direito de a cada dois anos submeter o aposentado por invalidez a perícias médicas para a verificação da incapacidade do segurado, como já descrito acima e conforme aduz Lei 8.213/91:

Art. 101. O segurado em gozo de auxílio-doença, aposentadoria por invalidez e o pensionista inválido estão obrigados, sob pena de suspensão do benefício, a submeter-se a exame médico a cargo da Previdência Social, processo de reabilitação profissional por ela prescrito e custeado, e tratamento dispensado gratuitamente, exceto o cirúrgico e a transfusão de sangue, que são facultativos. ${ }^{21}$

Em 30 de dezembro de 2014 foi publicada a Lei 13.063/14 que mudou a redação do artigo 101 da Lei 8213/91, conferindo de um certo modo um caráter definitivo para a aposentadoria por invalidez, em seu parágrafo $1^{\circ}$, diz o seguinte: " $\$ 1^{\circ} \mathrm{O}$ aposentado por invalidez e o pensionista inválido estarão isentos do exame de que trata o caput após completarem 60 (sessenta) anos de idade." 22

Contudo para Zambitte (2015, pg. 595) a mudança não tornou definitiva a aposentadoria por invalidez, como ocorria com a previsão da Consolidação das Leis de Previdência Social - CLPS, Decreto 89312/84, art. $30, \S 6^{\circ}$ e art. 101 da Lei $8213 / 91$, as quais liberavam o segurado das perícias aos 55 anos (porém foram suprimidas pela Lei 9032/95), mas apenas liberou os segurados com mais de 60 anos de se submeterem às perícias periódicas. Segundo ele, se o segurado voltar a trabalhar depois disso, ainda assim perderá o benefício.

No entanto nas seguintes situações o segurado com mais de 60 anos não ficará isento das perícias:

$\S 2^{\circ}$ Aisenção de que trata o $\S 1{ }^{\circ}$ não se aplica quando o exame tem as seguintes finalidades:

I - verificar a necessidade de assistência permanente de outra pessoa para a concessão do acréscimo de $25 \%$ (vinte e cinco por cento) sobre o valor do benefício, conforme dispõe o art. 45;

\footnotetext{
21 BRASIL. Lei dos Benefícios 8.213/91. Disponível em: < www.planalto.gov.br/CCIVIL_03/leis/L8213cons.htm> Acesso em 13/09/2015.

${ }^{22}$ Ibdem.
} 
II - verificar a recuperação da capacidade de trabalho, mediante solicitação do aposentado ou pensionista que se julgar apto;

III - subsidiar autoridade judiciária na concessão de curatela, conforme dispõe o art. $110{ }^{23}$

Assim ao completar 60 anos de idade poderá o segurado então descansar ao menos no que tange às perícias, que, diga-se de passagem, são um tanto cansativas em se tratando da estrutura oferecida pelas unidades de atendimento e também quanto à insegurança em que vive sem saber como será cada avaliação do perito.

\section{CONSIDERAÇÕES FINAIS}

O estudo concluiu que a lei prevê a reabilitação profissional ao segurado com intuito de prepará-lo para ser reinserido no mercado de trabalho.

Assim, depois de passar pelo programa de reabilitação profissional, tornando-se apto novamente ao trabalho, o segurado que retornar à empresa onde trabalhava, e não se readaptar, sendo mandado embora, ao buscar um novo emprego, a empresa que analisar o currículo de um ex aposentado por invalidez pode não querer correr o risco de contratar alguém nesta situação, ou seja, depois de analisar seu histórico, certamente este não será um candidato com grandes chances de contratação.

E é aqui que entra a questão da incapacidade social que consiste em que o segurado tendo recuperado a capacidade para o trabalho não consegue mais ter uma capacidade plena por diversos fatores ao qual ele está inserido, assim, muitos não terão condições de retornar ao mercado de trabalho.

Ainda sobre a Reabilitação Profissional o que podemos dizer é que o estudo não foi conclusivo no que tange aos resultados deste programa por demandar tempo para pesquisas em campo. Assim a sugestão é que doravante pudesse ser feito pesquisas voltadas a analisar se na realidade a legislação está efetivamente sendo cumprida, ou seja, uma pesquisa em campo para analisar se as APS estão cumprindo o que descreve a

${ }^{23}$ Ibdem. 
legislação, com entrevistas inclusive com o segurado em reabilitação. Um estudo em âmbito nacional, analisando todas as regiões do País. Coisa que não cabe numa pesquisa como essa, de um artigo científico, pois demanda estatísticas realizadas por um longo período.

Também ainda para concluir uma pesquisa mais avançada se faz necessário uma avaliação dos resultados, ou seja, um resultado positivo seria a diminuição das demandas judiciais desta natureza. Assim se a legislação está efetivamente sendo cumprida pelo INSS os resultados a longo prazo começarão a aparecer, ou seja, o segurado não terá necessidade de buscar o seu direito na seara judicial. Pois a princípio, a grosso modo, o que se percebe é que o INSS tem indeferido a maioria destes casos e que a seara judicial é quem está tendo que resolver estas questões.

\section{REFERÊNCIAS}

ALVARENGA, Rúbia Zanotelli de Alvarenga. A Aposentadoria por Invalidez e a Manutenção do Plano de Saúde. Disponível em: http://www.facefaculdade.com.br/arquivos/revistas/A_Aposenn tadoria_por_Invalidez_e_a_Manuteno_do_Plano_de_Sade.pdf.

BRASIL. Constituição Federal de 1988. Disponível em: www.planalto.gov.br/ccivil_03/Constituicao/Constituicao.htm. Acesso em 13/10/2015.

BRASIL. Decreto 3.048/99. Disponível em: < www.planalto.gov.br/ccivil_03/decreto/d3048.htm> Acesso em 13/09/2015.

BRASIL. Lei dos Benefícios 8.213/91. Disponível em: < www.planalto.gov.br/CCIVIL_03/leis/L8213cons.htm> Acesso em 13/09/2015.

BRASIL. Súmulas - TST. Disponível em: www.tst.jus.br/sumulas. Acesso em 15/12/2015.

BRASIL. Súmulas STF - Supremo Tribunal Federal. Disponível em: www.stf.jus.br/portal/cms/verTexto.asp?servico=jurisprudencia Sumula. Acesso em 15/12/2015.

IBRAHIM, Fábio Zambitte. Curso de Direito Previdenciário. Niterói, RJ: Impetus, 21 ed., 2015.

INSTRUÇÃO NORMATIVA INSS/PRES N ${ }^{\circ}$ 77, DE 21 DE JANEIRO DE 2015 - DOU DE 22/01/2015 - Alterada. Disponível em: 
www3.dataprev.gov.br/sislex/paginas/38/insspres/2015/77.htm. Acesso em 15/12/2015.

Jurisprudências - Disponível

em: www.jusbrasil.com.br/.../busca?...reabilitação+profissional\%2C...aposent...> Acesso em 24/11/2015.

MORAIS, Lindocastro Nogueira, Dissertação de Pós. Apud RIBEIRO, Juliana de Oliveira Xavier. Atualidades sobre o auxílio-doença. In: FOLMANN, Melissa (coord). Previdência nos 60 anos da declaração de direitos humanos e nos 20 da Constituição Brasileira. Curitiba: Juruá, 2008, p.189190.

PULINO, Daniel. A aposentadoria por invalidez no Direito Positivo Brasileiro. São Paulo: LTr, 2001.

Trabalho apresentado no Ciclo de Estudos de Direito do Trabalho, Angra dos Reis (Rio de Janeiro), 28 de maio de 2005. Disponível em: Artigos: www.josepastore.com.br/artigos/rt/rt_246.htm) - acesso em $04 / 11 / 2015$. 